\title{
Dehydrogenation Catalyst for Organic Hydride on the Basis of Superheated Liquid-Film Concept
}

\author{
A. Shono ${ }^{1}$, M. Naya ${ }^{1}$, K.Otake ${ }^{1}$, D. Kobayashi ${ }^{2, *}$, S. Kobayashi ${ }^{2,3}$ and Y. Saito ${ }^{3}$ \\ ${ }^{1}$ Department of Industrial Chemistry, Faculty of Engineering, Tokyo University of Science, Tokyo, Japan \\ ${ }^{2}$ Department of Green and Sustainable Chemistry, Tokyo Denki University, Tokyo, Japan \\ ${ }^{3}$ New Energy Lab., Inc., Tokyo, Japan
}

\begin{abstract}
Reversible reaction couples of hydrogenation and dehydrogenation of organic compounds e.g. methylcyclohexane and toluene, or 2-propanol and acetone, are described in terms of hydrogen supplier to fuel cells, which will satisfy our demands of combined heat and power at various compact sizes. Carbon supported nano-sized metal particles, wetted with the liquid substrate in a reactor, was used for conversion of organic hydrides into hydrogen and organic compounds, being separable by distillation. Vigorous nucleate boiling is important for heat transfer as well as for irreversible bubble evolution, leading hydrogen to the vapor phase. Once the bubble is broken at the interface, catalytic hydrogenation will be prohibited, because gaseous hydrogen is unable to dissolve into the boiling liquid. Catalytic dehydrogenation under superheated liquid-film conditions can thus convert low-quality heats into hydrogen energy.
\end{abstract}

Keywords: Dehydrogenation catalyst, Organic hydride, Superheated liquid-film.

\section{INTRODUCTION}

As a storable and transportable hydrogen carrier, organic hydride can take a mediator role in energy supply chain [1], being initiated with renewable energies and utilized finally at local and small-scaled applications. In contrast to facile hydrogenation reactions, endothermic dehydrogenation should include for this purpose such difficult performances as perfect conversion at temperatures as low as possible by adopting a compact-sized reactor.

Under nucleate boiling conditions [2], superheated liquid of organic hydride was enforced to contact with catalytically-active sites after frequent removal of bubbles, by which generated hydrogen was carried out efficiently to the gas phase without return. Moreover, nano-sized metal particles supported on microporous carbon must properly be immersed with organic hydride e.g. 2-propanol, decalin or methylcyclohexane, under steep temperature gradients [3].

In the present paper, simultaneous reaction procedures of both perfect conversions and high liquidhourly space velocities (LHSV) are explored upon the basis of irreversible thermodynamics in order to perform reactor design for supplying hydrogen to operate solid oxide fuel cell (SOFC) in domestic scales.

*Address correspondence to this author at the Department of Green and Sustainable Chemistry, Tokyo Denki University, Tokyo, Japan; Tel: 81-3-52845443; E-mail: kobayashi@mail.dendai.ac.jp

\section{EXPERIMENTAL}

\subsection{Catalyst Support}

Highly-porous carbon granule and carbon cloth were adopted as catalyst-support materials. Granular particles $(7 \mu \mathrm{m})$ were made by steam activation with potassiumhydroxide from palm shell (Kansai Netsu Kagaku Co.), being bestowed with large surface area (3100 $\mathrm{m}^{2} \mathrm{~g}^{-1}$ by the BET method), huge micropore volume $\left(1.78 \mathrm{mLg}^{-1}\right)$ and small micropore diameter (2 $\mathrm{nm})$. These characteristics were brought from such processes that graphitic carbon layers were selectively eroded with repeated reactions of $\mathrm{C}+\mathrm{KOH} \rightarrow \mathrm{CO}+$ $1 / 2 \mathrm{H}_{2}+\mathrm{K}$ and $\mathrm{K}+\mathrm{H}_{2} \mathrm{O} \rightarrow \mathrm{KOH}+1 / 2 \mathrm{H}_{2}$ during activation. On the contrary, carbon fibres were made by tugging-calcination of poly-acrylonitrile and woven into carbon cloth with plenty nano-cracks of $1.5 \mathrm{~nm}$ width with the BET surface area of $1834 \mathrm{~m}^{2} \mathrm{~g}^{-1}$ (Kuraray Chemicals Co.).

Organic hydrides are accepted into these micropores at low temperatures, left inside due to capillary condensation at higher temperatures and possible to migrate over the carbon surface as liquid even at superheated temperatures.

\subsection{Catalyst Metal}

Carbon-supported platinum catalysts (5 wt\%)were prepared from an aqueous solution of $\mathrm{K}_{2} \mathrm{PtCl}_{4}$ by stirring with the granular carbon, which had been treated with a concentrated $\mathrm{NaOH}$ aqueous solution. Base treatment would change the micropore structures 
of granular carbon. Indeed pretreatment at $\mathrm{pH} 14$ was revealed to reduce the specific surface area to 1925 $\mathrm{m}^{2} \mathrm{~g}^{-1}$ and the micropore volume to $0.97 \mathrm{mLg}^{-1}$, but the pore diameter was ascertained to retain the magnitude of $2 \mathrm{~nm}$. Valency of $\mathrm{PtCl}_{4}{ }^{2-}$ was reduced to metallic $\mathrm{Pt}$ with a hot aqueous solution of $\mathrm{NaBH}_{4}$, which was followed by water washing and prolonged heating evacuation. The average diameter of well-dispersed platinum particles was obtained as $2.7 \mathrm{~nm}$ in an electron-microscope image [4]. High particle dispersion would originally be ascribed to the ligand exchange of $\mathrm{PtCl}_{4}{ }^{2-}$ into $\mathrm{Pt}(\mathrm{OH}) \mathrm{Cl}_{3}{ }^{2-}$ inside the micropore of basepretreated carbon, since it would be presumed for platinum to coordinate with any hydrophilic group of carbon through strong mediation of the $\mathrm{OH}$ ligand and to be reduced into scattered atoms all over the granule. Composite catalysts of either $\mathrm{Pt}-\mathrm{Fe} / \mathrm{C}$ or $\mathrm{Pt}-\mathrm{Ir} / \mathrm{C}$ were prepared similarly from the mixed aqueous solution of $\mathrm{K}_{2} \mathrm{PtCl}_{4}$ and $\mathrm{FeCl}_{3}$ or $\mathrm{K}_{2} \mathrm{PtCl}_{4}$ and $\mathrm{IrCl}_{3}$ by impregnation. Another composite couple of $\mathrm{Pt}-\mathrm{Re}$ was made from mixing of the $\mathrm{Pt} / \mathrm{C}$ catalyst and $\operatorname{Re}\left(\mathrm{C}_{5} \mathrm{H}_{5}\right)(\mathrm{CO})_{2}$ at $240^{\circ} \mathrm{C}$ under hydrogen atmosphere.

Platinum catalysts supported on carbon cloth (5 wt $\%$ ) were prepared by a similar impregnation method. A certain amount of carbon cloth, pre-evacuated at $150^{\circ} \mathrm{C}$ for $1 \mathrm{~h}$, was immersed and stirred for $24 \mathrm{~h}$ with an aqueous solution of $\mathrm{K}_{2} \mathrm{PtCl}_{4}$, which was followed by $\mathrm{NaBH}_{4}$ reduction. After water-washing, filtering and drying in vacuo at $200^{\circ} \mathrm{C}$ for $5 \mathrm{~h}$, platinum particles supported on carbon cloth were cut into circular and rectangular shapes before setting to the reactor for hydrogen generation. According to electron-microscope image, nano-sized platinum particles were certainly prepared, but homogeneous dispersion was difficult on carbon cloth.

\subsection{Reaction Apparatus}

Both batch-wise and flow-type reactors were used for generating hydrogen from organic hydrides [5].

Batch-wise pursuit of catalysis was performed with a set of round-bottom flask, oil bath, refluxing condenser and gas burette (Figure 1a). A certain amount of granular catalyst and various amounts of organic hydride were set inside the flask, from which hydrogen was transferred to gas burette under reactive distillation conditions.

A flow-type rector was consisted of carbon-cloth catalyst laid on a pan, circular ring for spraying substrate liquid, mantle-and block-shaped electric heaters monitored with thermocouples, refluxing condenser and gas flow meter (Figure 1b). Spray rings with three and six holes were examined to know whether poring densities of liquid toward the carboncloth catalyst and distribution rates of substrate over the catalyst surface could affect the reaction rates or not.

Another flow-type reactor was different concerning style of substrate feed and mode of catalyst packing. The granular-carbon catalyst was set in a $1 / 4$ inch stainless tube with length of $6 \mathrm{~cm}$, containing inlet packing of carbon cloth $(0.5 \mathrm{~cm})$, preheating zone of granular carbon $(3 \mathrm{~cm})$, reaction zone of granular catalyst $(2 \mathrm{~cm})$ and outlet packing of carbon cloth $(0.5$ $\mathrm{cm})$. Substrate liquid was fed from the bottom, heated

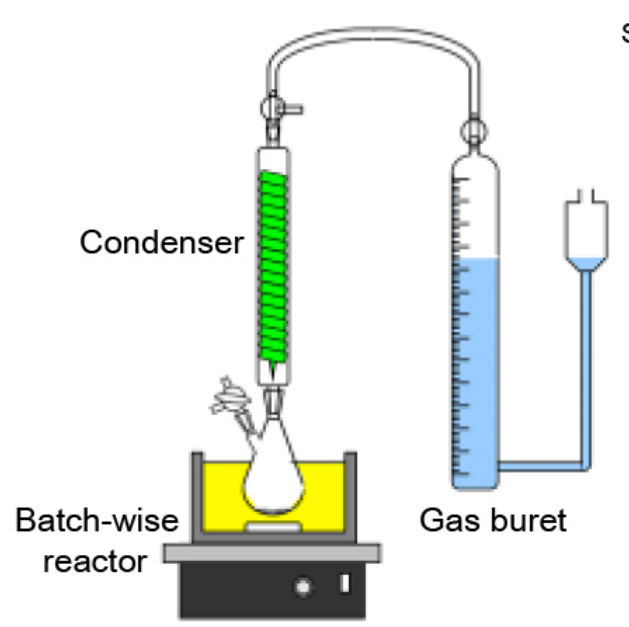

(a) Batch-wise reactor

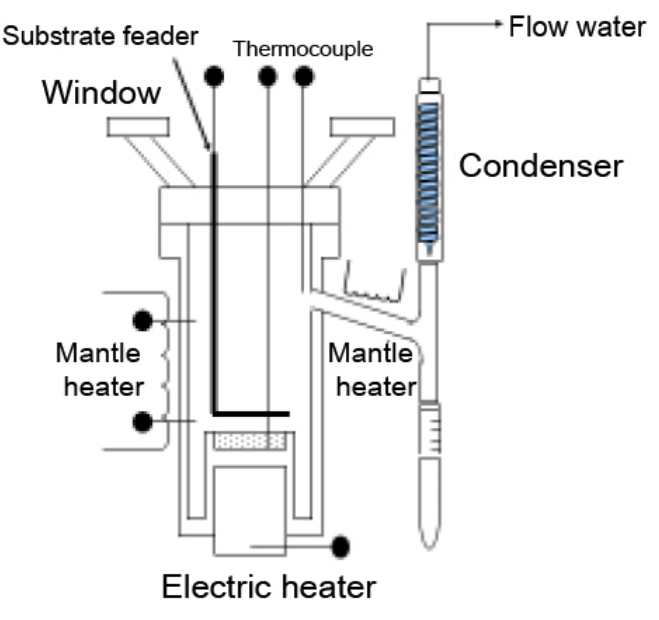

(b) Flow-type reactor

Figure 1: Experimental apparatus for catalytic dehydrogenation under boiling and refluxing conditions in batch-wise or flow-type operation. 


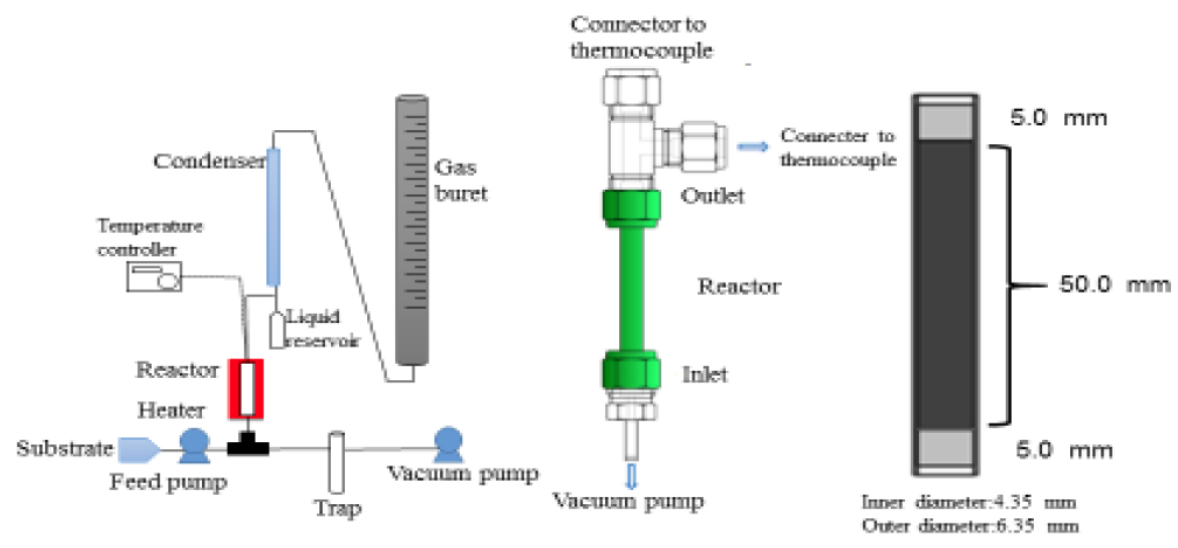

Flow-type system for dehydrogenation

Reactor in detail

Figure 2: Experimental apparatus for catalytic dehydrogenation under boiling conditions in continuous operation with tubular flow reactor.

gradually, evolved hydrogen accompanying evaporation, and then removed out as a gaseous mixture (Figure 2).

\subsection{Reaction Procedure}

Platinum nano-particles supported on highly-porous carbon must be wetted with superheated substrate liquid, even though it was fed at ambient temperatures irrespective of the reactor, either batch-wise or flowtype.In a flow-type reactor (Figure 1b), liquid-phase substrate was supplied continuously to a certain amount of the $\mathrm{Pt} / \mathrm{C}$ catalyst at various feed rates under atmospheric pressure. All vapors were removed from the reactor via a thermally protected part by a refluxing condenser. After confirming the reaction to be stationary, hydrogen generation rates were recorded every $5 \mathrm{~min}$ for $30 \mathrm{~min}$ with a flow meter, and the condensate composition was analyzed gaschromatographically. Since the substrate was fed as droplets from a ring-shaped feeder to the catalyst in a flat-bottomed round vessel, nano-sized platinum had to be supported on carbon cloth in order to avoid jumping of the granular catalyst due to substrate droplets. Two kinds of hole densities for sending the same amount of substrate were attempted with respect to the feeder ring, one concentrated (three holes) and the other dispersed (six holes). The catalyst-layer temperatures were measured with a thermocouple, set at the bottom of the catalyst carbon-cloth.

Properly-wetted states under steep temperature gradient were essentially important for enhancing the rates of hydrogen generation and the extents of conversion. Reaction procedures should be controlled to avoid i) gas-solid contact caused by drying up, ii) liquid-flooding to diminish temperature gradient, iii) useless evaporation from bulk liquid and iv) liquid-feed channeling induced by excessive flow.

The amount ratio of substrate liquid to catalyst solid seems to be decisive for efficient hydrogen generation in batch-wise procedures, whereas proper feed rates of substrate must be chosen for flow-type operations in order to keep the catalyst under superheated liquid-film conditions.

\section{RESULTS}

\subsection{Batch-Wise Dehydrogenation of 2-Propanol}

In the batch-wise reactor, hydrogen generation was pursued under boiling and refluxing conditions by heating at $90^{\circ} \mathrm{C}$ and cooling at $5^{\circ} \mathrm{C}$ for $2.0 \mathrm{~h}$, where a constant amount of granular catalyst $(1.01 \mathrm{~g})$ and various amounts of 2-propanol (2.0, 3.0, 4.0, 5.0 and $10.0 \mathrm{~mL}$ ) were laid in a round-bottom flasks, as shown in Figure 3. Catalytic behaviors were quite sensitive to the amounts of 2-propanol. The optimum liquid-solid amount ratio for the catalyst of $1.01 \mathrm{~g}$ became 2propanol of $4.0 \mathrm{~mL}$. As for the region of high liquid/solid ratios as 5.0 and $10.0 \mathrm{~mL}$, the larger substrate amount gave the smaller catalytic activity. On the contrary, the substrates as scarce as 2.0 and $3.0 \mathrm{~mL}$ resulted in two catalysis phases i.e. initial rapid and later suppressed generation of hydrogen even under the same reaction conditions.

Hydrogen generation (2h) was correlated with the charged amount in Figure $\mathbf{4 a}$, exhibiting a maximum at $4.0 \mathrm{~mL}$ substrate, which was indifferent to the kinds of metal species, either platinum alone or platinum-iron composite. The present tendency may suggest that the 


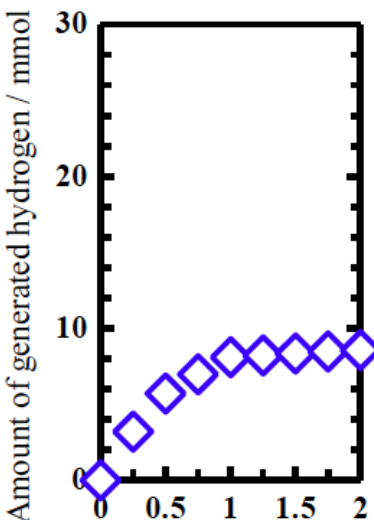

Reaction time / h

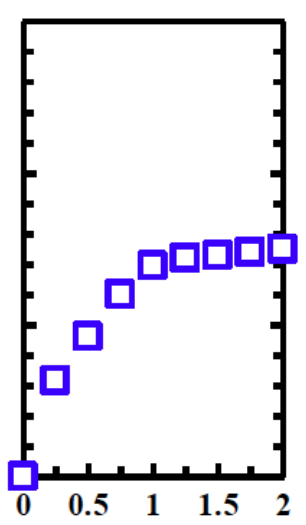

Reaction time / h

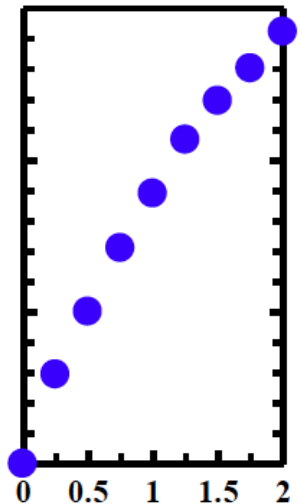

Reaction time / h

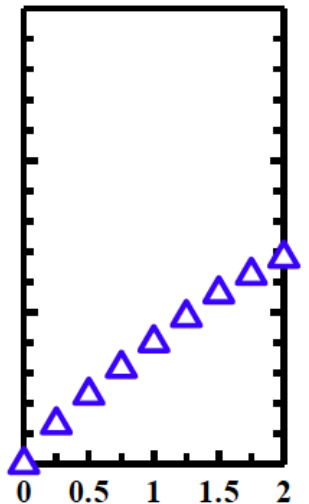

Reaction time / h

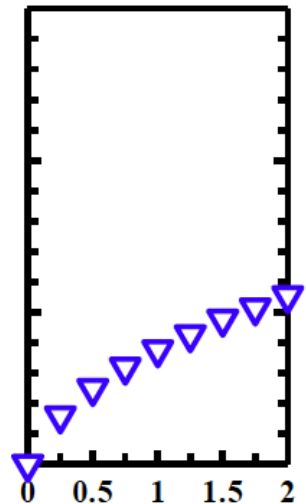

Reaction time / h

Figure 3: Dehydrogenation of catalysis for 2-propanol in a batch-wise reactor. Relationship between reaction rates and charged amounts of substrate.

Time course of hydrogen generation with carbon-supported platinum-iron catalyst at variously-charged amount of 2-proponal. Charged amount: $2.0(\diamond), 3.0(\square), 4.0(\bullet), 5.0(\Delta)$, and $10.0 \mathrm{~mL}(\nabla)$.

Catalyst: composite nanoparticles supported on the granular activated carbon (Pt-Fe (10:1)/C 5 wt-metal\%, $1.01 \mathrm{~g})$. Reaction conditions: boiling and refluxing by heating at $90^{\circ} \mathrm{C}$ and cooling at $5^{\circ} \mathrm{C}$.
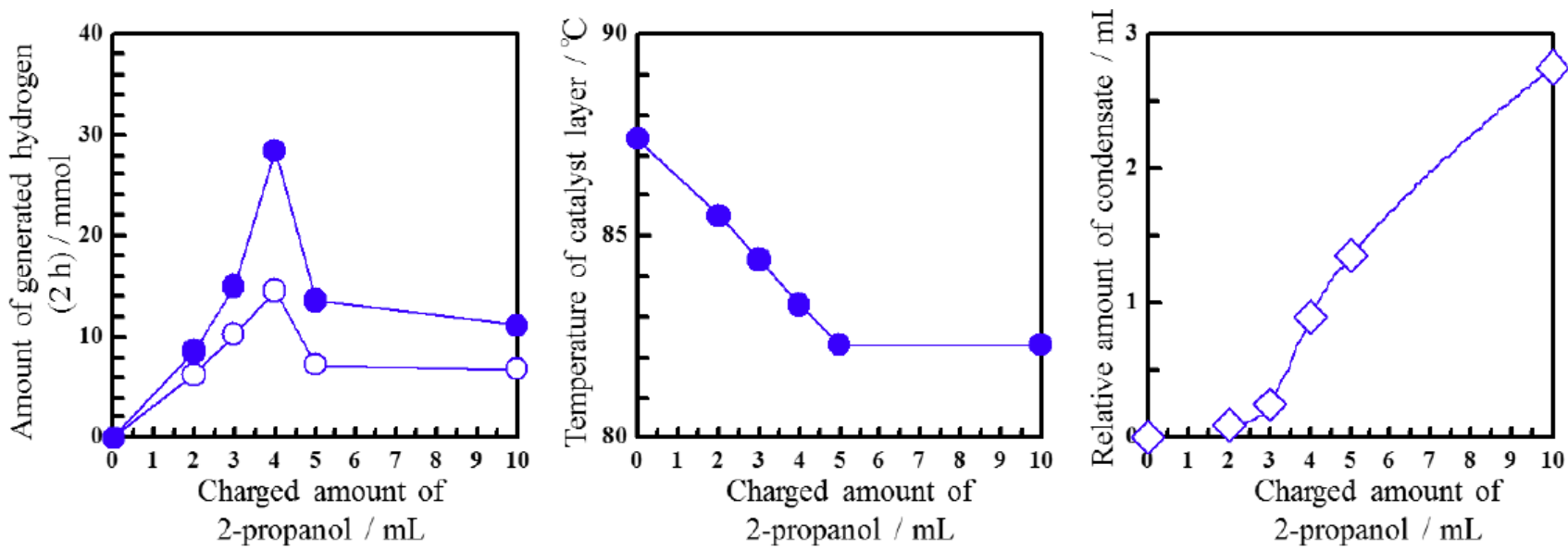

Figure 4: Dehydrogenation (a), catalyst temperature (b), and evaporation (c) for 2-propanol in the batch-wise reactor.

(a) Relationship between catalytic dehydrogenation activities and charged amounts of 2-propanol with carbon-supported platinum-iron composite $(\bullet)$ and platinum alone $(\circ)$ catalysts.

(b) Temperatures monitored with a thermocouple inside the catalyst layer as a function of charged amounts of 2-propanol (•).

(c) Evaporation rates from the granular carbon support pursued by measuring dropped-down condensate relatively as a function of charged amounts of 2-propanol $(\diamond)$.

maximum is not determined by the kinds of catalytic active sites but by the supporting carbon. Plenty amounts of micropores would be useful for substrates, which were kept in the liquid phase under working conditions. Interestingly, the catalyst-layer temperature realizing the maximum activity $(4.0 \mathrm{~mL}$-substrate) was higher than the boiling point $\left(82.4^{\circ} \mathrm{C}\right)$ but lower than that of the sandbath $(0 \mathrm{~mL})$, as shown in Figure $\mathbf{4 b}$. Thus the catalytic active sites could take their important role, where capillary-condensed substrates in the carbon micropores would migrate on surface as superheated liquid toward the nano-metal sites.
Relative evaporation rates were depicted in Figure 4c. Evaporation was rather suppressed in the scarce region $(<3 \mathrm{~mL})$, which was quite different from the plenty region $(>4 \mathrm{~mL})$. This might be expected from the contrast between capillary-condensed liquid and bulk liquid. Excess amounts of charged substrate would consequently result in not only reducing the catalystlayer temperature from the external-heating temperature down to the boiling point, but also for the liquid substrate to evaporate in vain without chances to react. 

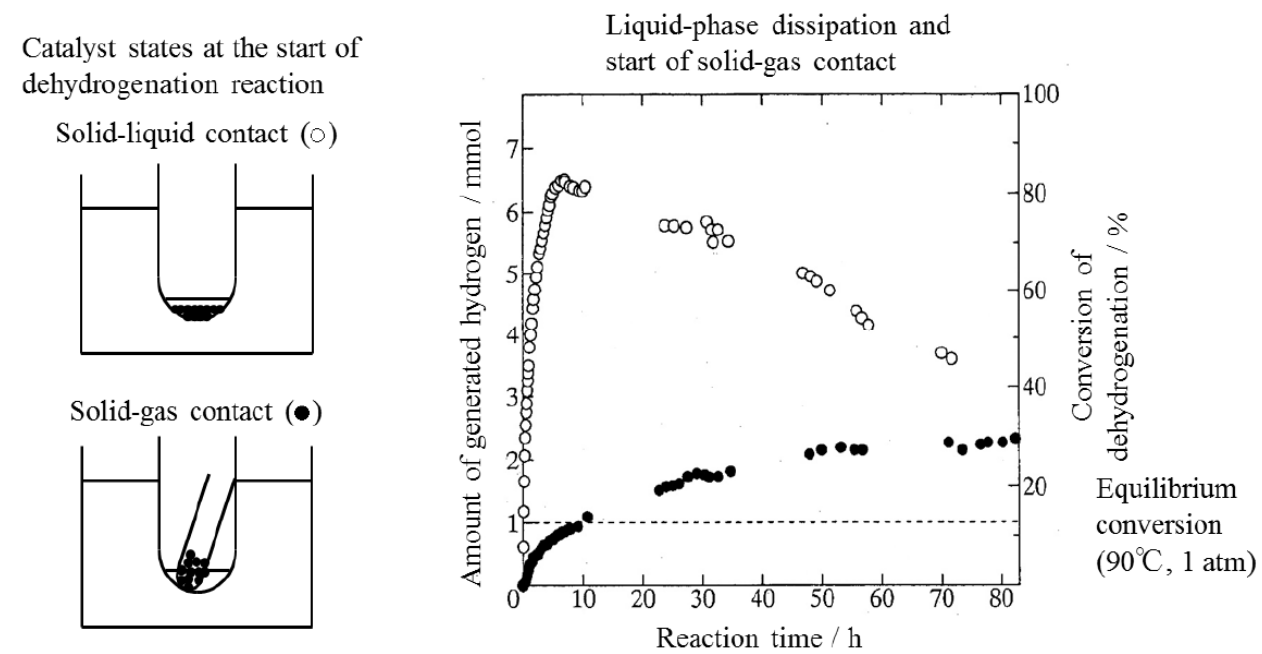

Figure 5: Batch-wise dehydrogenation of 2-propanol as contrasted in catalyst/substrate contact modes between solid-liquid and solid-gas.

Time courses of hydrogen amounts generated from different states of catalysts immersed in liquid 2-propanol ( $\circ$ ) and adsorbed with gaseous 2-propanol $(\bullet)$ at the start of reaction. Charged amount of 2-propanol: $0.6 \mathrm{~mL}$, Catalyst: Platinum-ruthenium composite nanoparticles supported on the granular activated carbon (Pt-Ru (1:1)/C 22 wt-metal\%, $0.09 \mathrm{~g}$ ), Reaction conditions : Boiling and refluxing by heating at $90^{\circ} \mathrm{C}$ and cooling at $5^{\circ} \mathrm{C}$.

The catalyst/substrate contact of solid-gas or solidliquid was compared in order to contrast the ordinary heterogeneous mode to the superheated liquid-film mode (Figure 5). Evaporated substrate could contact with the granular catalyst only inside a narrow glass tube and gave hydrogen at a steady but rather low reaction rate all through the period. Since hydrogen was separated from condensates under refluxing conditions, conversion levels of dehydrogenation became higher than equilibrium owing to reactive separation, as realized in this solid-gas catalysis. However, the same granular catalyst generated hydrogen in a peculiar manner, when immersed with a carefully-chosen amount of substrate. Rapid evolution upto a high conversion over $80 \%$ was followed by sudden stop and by gradual decrease of gas volume, approaching to another conversion limit. In appearance, new limit is aiming at the same one with solid-gas contact. When the precharged liquid substrate was all evaporated volume increase was stopped. From the moment of observed stoppage, the catalyst surface would be enforced to contact directly with the gaseous components. The volume decrease should be attributed to solid-gas catalysis between hydrogen and acetone. Thus the presumption that the superheated liquid-film conditions would promote dehydrogenation beyond equilibrium was instituted.

\subsection{Batch-Wise Dehydrogenation of Decalin}

Hydrogen generation for $2.5 \mathrm{~h}$ from a constant amount of granular catalyst $(0.30 \mathrm{~g})$ and various amounts of decalin $(0.5,0.75,1.0,1.25,1.5$ and $3.0 \mathrm{~mL}$ ) was investigated under boiling and refluxing conditions in the batch-wise reactor by heating at $210^{\circ} \mathrm{C}$ and cooling at $5^{\circ} \mathrm{C}$ (Figure 6).

As shown in Figure $\mathbf{7}$, the correlation pattern between the amounts of generated hydrogen and charged decalin was similar to 2-propanol (Figure 4a). The catalyst-layer temperature at the optimum ratio of $0.30 \mathrm{~g}$-catalyst $/ 1.0 \mathrm{~mL}$-decalin was observed also to be higher than the boiling point $\left(192^{\circ} \mathrm{C}\right)$ and lower than the heating temperature $\left(210^{\circ} \mathrm{C}\right)$, as shown in Figure 8 like 2-propanol (Figure 4b).

Under common boiling and refluxing conditions of heating externally at $210^{\circ} \mathrm{C}$ and refluxing at $5^{\circ} \mathrm{C}$, the temperatures of a constant amount of granular activated carbon $(0.285 \mathrm{~g})$ immersed with decalin $(0,10$, and $3.0 \mathrm{~mL})$ were measured by inserting a thermocouple directly (Figure 9a). In the suspension state $(3.0 \mathrm{~mL})$, the catalyst-layer temperature was almost equal to the boiling point of decalin $\left(192^{\circ} \mathrm{C}\right)$, whereas the temperature in the liquid-film state $(1.0 \mathrm{~mL})$ was kept at the level just between the external heating temperature $\left(210^{\circ} \mathrm{C}\right)$ and the boiling point $\left(192^{\circ} \mathrm{C}\right)$. In case of the sand bath state $(0 \mathrm{~mL})$, its temperature was close to the heating temperature of $210^{\circ} \mathrm{C}$. By raising the external heating temperature from $210^{\circ} \mathrm{C}$ to $280^{\circ} \mathrm{C}$, the temperatures of the liquid-film state $(1.0 \mathrm{~mL})$ were elevated in accordance with the heating temperatures (Figure 9b). 


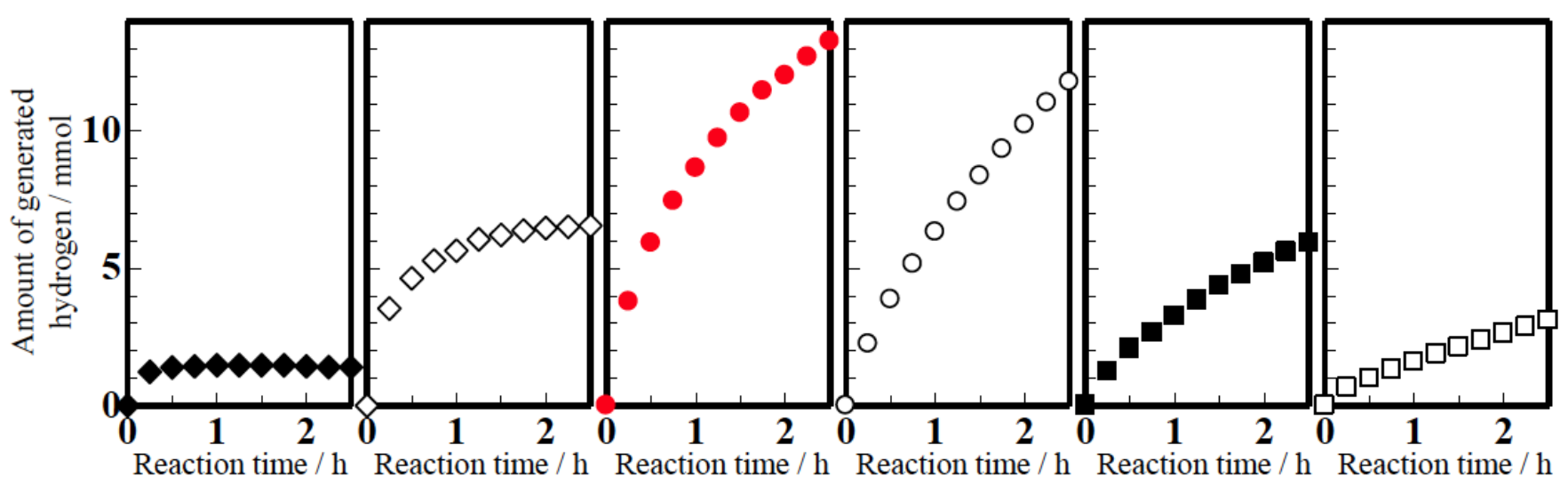

Figure 6: Dehydrogenation catalysis for decalin in the batch-wise reactor. Relationship between reaction rates and charged amounts of substrate.

Time courses of hydrogen generated from decalin with carbon-supported platinum catalyst at various charged amounts of decalin in the batch-wise reactor. Charged amount of decalin: $0.5(\diamond), 0.75(\diamond), 1.0(\bullet), 1.25(\circ), 1.5(\square)$, and $3.0 \mathrm{~mL}(\square)$. Catalyst: Platinum nanoparticle supported on the granular activated carbon (Pt/C $5 \mathrm{wt} \%, 0.30 \mathrm{~g}$ ). Reaction conditions: Boiling and refluxing by heating at $90^{\circ} \mathrm{C}$ and cooling at $5^{\circ} \mathrm{C}$.

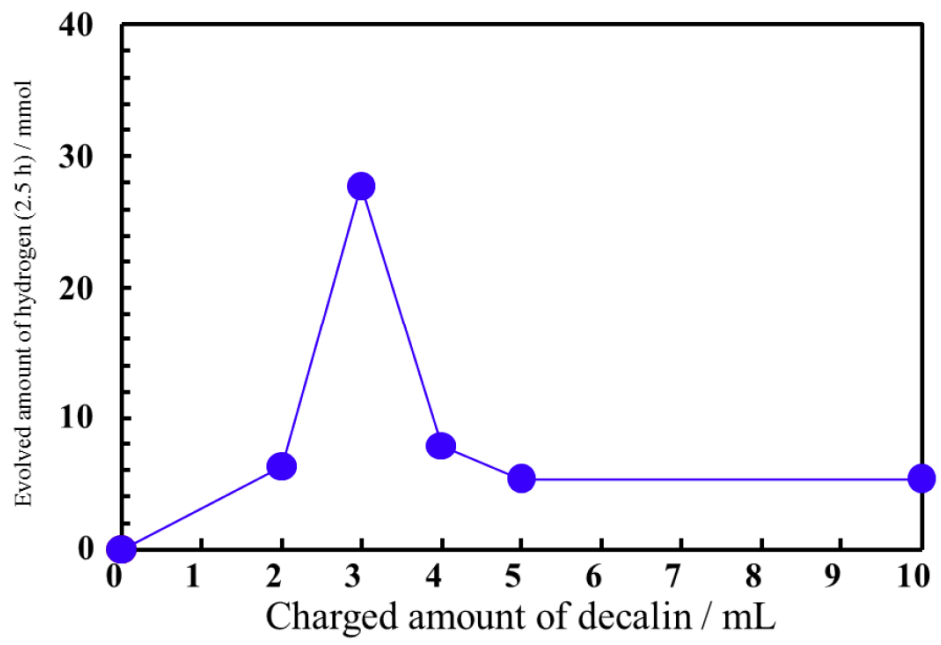

Figure 7: Relationship between catalytic dehydrogenation activities and charged amounts of decalin with use of carbonsupported platinum catalyst in the batch-wise reactor.

Amounts of hydrogen generated for $2.5 \mathrm{~h}$ from decalin as a commercial mixture of cis and trans-isomers (bp: $192{ }^{\circ} \mathrm{C}$ ) with $\mathrm{Pt} / \mathrm{C}$ catalyst $(5 \mathrm{wt} \%, 0.75 \mathrm{~g})$ under boiling and refluxing conditions by heating at $210{ }^{\circ} \mathrm{C}$ and cooling at $5{ }^{\circ} \mathrm{C}$.

In Figure 10a, time courses for decalin dehydrogenation with a Pt-Re composite catalyst were depicted at various heating temperatures. Complete conversion of decalin into naphthalene and hydrogen was attained by heating externally at $280^{\circ} \mathrm{C}$. Initial reaction rates were well correlated with heating temperatures in the Arrhenius plots of Figure 10b.

\subsection{Batch-Wise and Flow-Type Dehydrogenation of Methylcyclohexane}

Sharp contrast in hydrogen generation from methylcyclohexane was demonstrated among the catalyst-layer states of scarce, adequate and excess amounts for pre-immersing the catalyst $(0.30 \mathrm{~g})$ (Figure
11). In the scarce-amount case $(0.4 \mathrm{~mL})$, initial rapid generation was immediately changed to poor reactivities, whereas the reaction rate was suppressed all through the period in case of the excess amount (1.2mL).

Methylcyclohexane could be converted with the Pt-Ir composite catalyst $(0.30 \mathrm{~g})$ into toluene and hydrogen almost completely at $210^{\circ} \mathrm{C}$ after the $2.0 \mathrm{~h}$ period, only when the adequate amount of substrate $(0.8 \mathrm{~mL})$ was charged initially. Importance of the solid/liquid contact ratio should be noted for catalytic dehydrogenation of methylcyclohexane as well under boiling and refluxing conditions. 


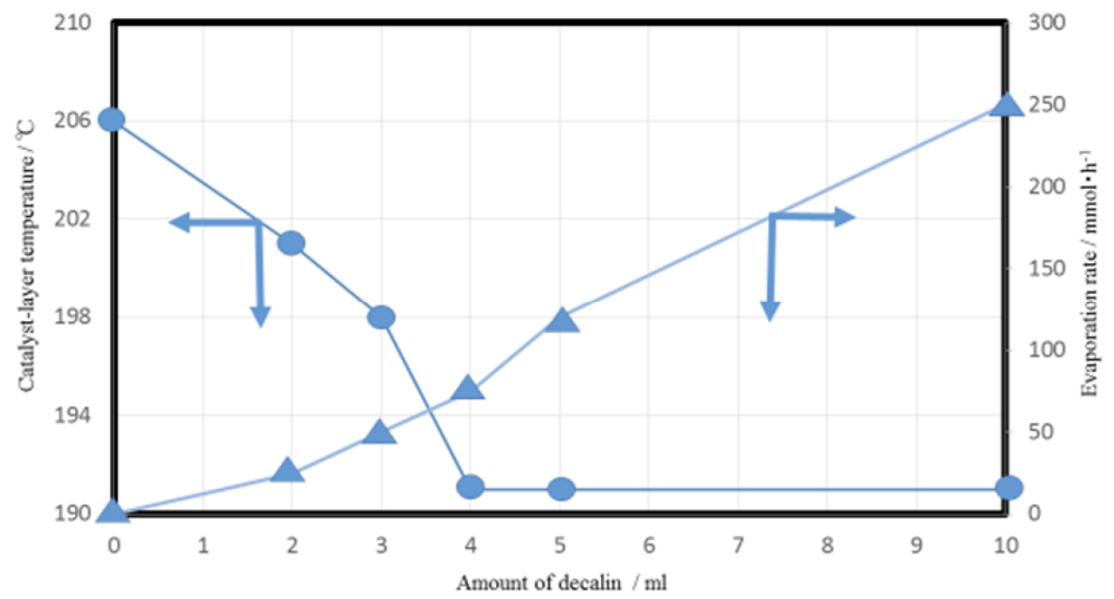

Figure 8: Correlation of charged decalin amounts with catalyst-layer temperatures and evaporation rates. The carbon support without metal was set inside the batch-wise reactor.

Catalyst: Pt/C (5 wt\%) $0.75 \mathrm{~g}$. Reaction conditions: Boiling and refluxing by heating at $210^{\circ} \mathrm{C}$ and cooling at $5^{\circ} \mathrm{C}$.
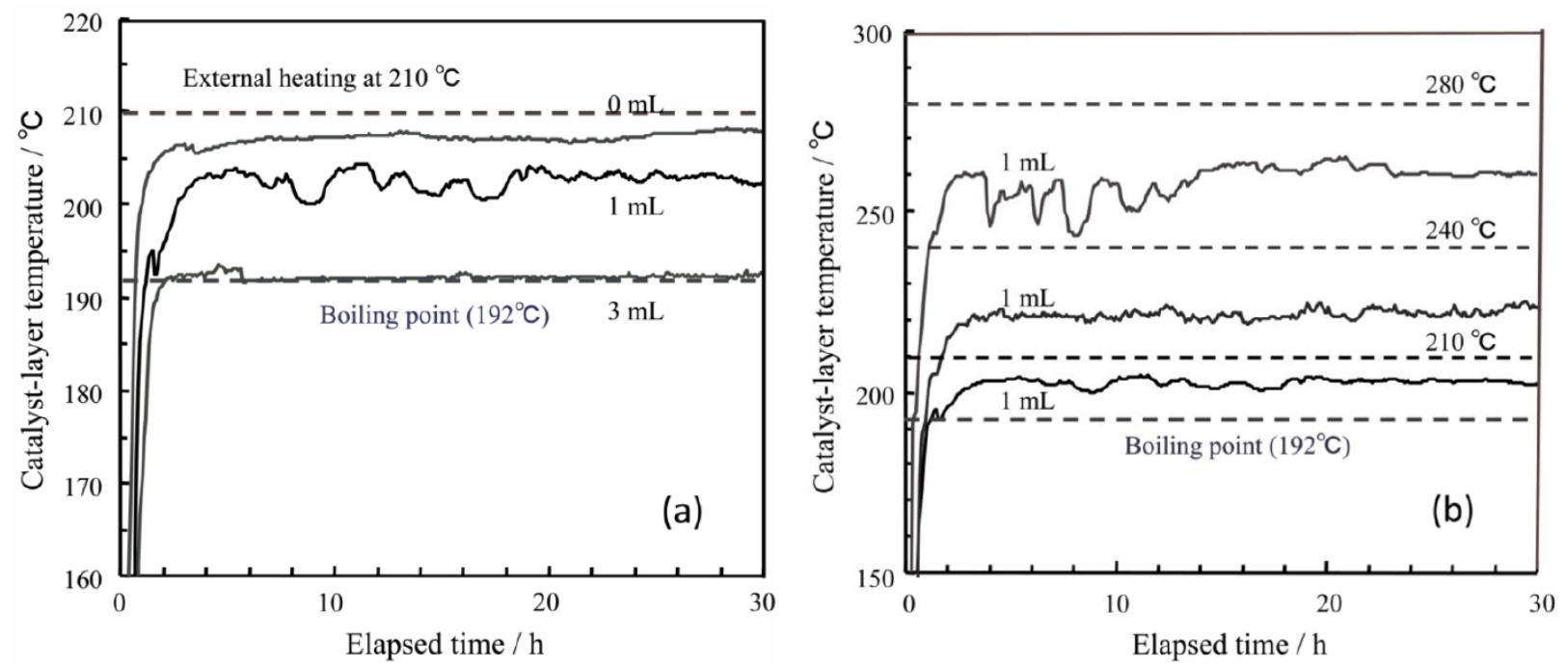

Figure 9: Correlation of catalyst-layer temperatures with the charged amounts of decalin (a) and the effect of the external heating (b) in the batch-wise reactor.

Charged amount of decalin: $0,1.0$, and $3.0 \mathrm{~mL}$, Temperature: Monitoring with a thermocouple inserted to granular activated carbon adopted as catalyst support $(0.285 \mathrm{~g})$, Boiling and refluxing : External heating at $210^{\circ} \mathrm{C}, 240^{\circ} \mathrm{C}$, and $280^{\circ} \mathrm{C}$ and $\mathrm{cooling}$ at $5^{\circ} \mathrm{C}$.

In Figure 12, hydrogen generation from cyclohexane, methylcyclohexane or decalin in the batch-wise reactor was compiled for a common liquidfilm state at the same catalyst $(0.30 \mathrm{~g}) /$ substrates $(1.0 \mathrm{~mL})$ ratio. Methycyclohexane exhibited the highest reactivity among these naphthenic substrates, as exemplified in the time course at $240^{\circ} \mathrm{C}$.

Superior reactivities in the liquid-film states over the suspended states were ascertained at the common heating temperature of $210^{\circ} \mathrm{Cfor}$ all of these substrates. Activation energies for methylcyclohexane and decalin were given from the Arrhenius plots (Figure 13).
As shown in Figure 14a, methlcyclohexane conversions into toluene and hydrogen were correlated with the substrate feed rates as monotonous decreasing curves irrespective of the densities of feedliquid holes in the flow-type reactor (Figure 1b). In all cases, conversions were enhanced at low feed rates and at high temperatures. Under the conditions investigated, the highest conversion was attained at the substrate feed rate of $0.39 \mathrm{mmolmin}^{-1}$ and the catalystlayer temperature of $330^{\circ} \mathrm{C}$. The magnitude of conversion was larger than $90 \%$. 

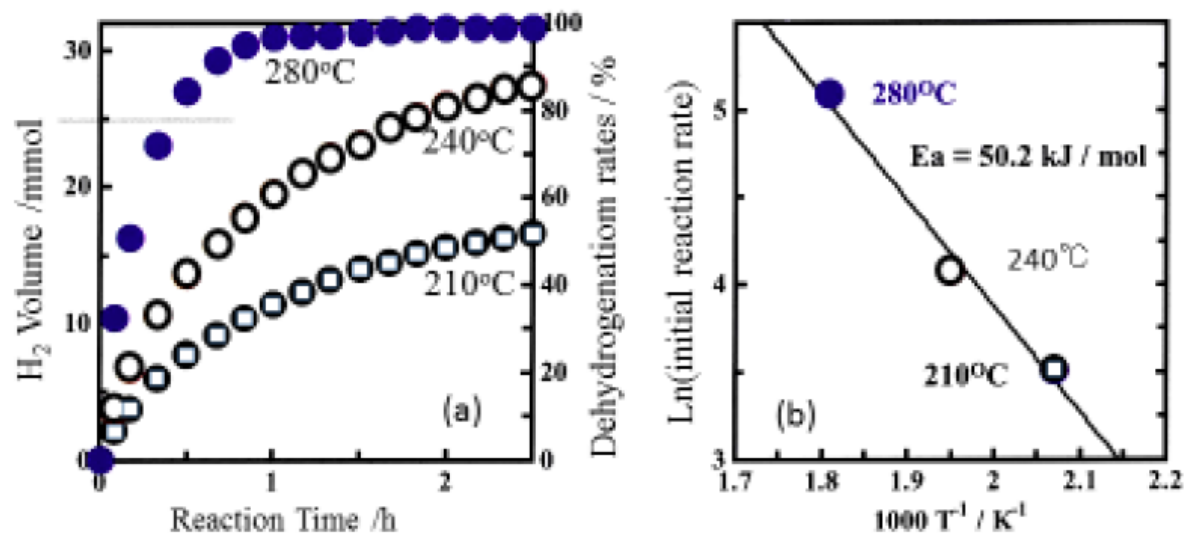

Figure 10: Dependence of catalytic dehydrogenation rates on external heating temperatures for decalin in the batch-wise reactor (a) and Arrhenius plot (b).

Catalyst: Pt-Re/C (molar ratio 4:1, 5 wt-Pt\%, $0.30 \mathrm{~g}$ ) immersed in decalin $1.0 \mathrm{~mL}$. Reaction conditions: Boiling and refluxing by heating at $210^{\circ} \mathrm{C}, 240^{\circ} \mathrm{C}$, and $280^{\circ} \mathrm{C}$, and cooling at $5^{\circ} \mathrm{C}$. Arrhenius analysis: Activation energy from initial reaction rates.

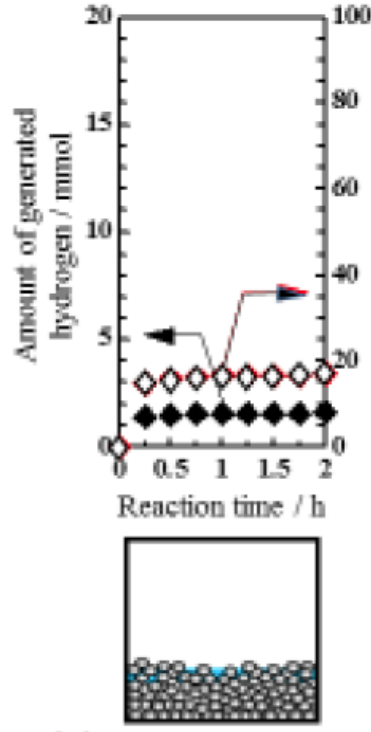

(a) Solid-gas contact immediately after start
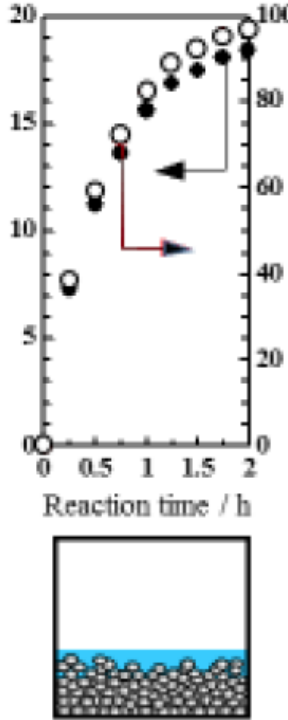

(b) Supetheated liquid-film state

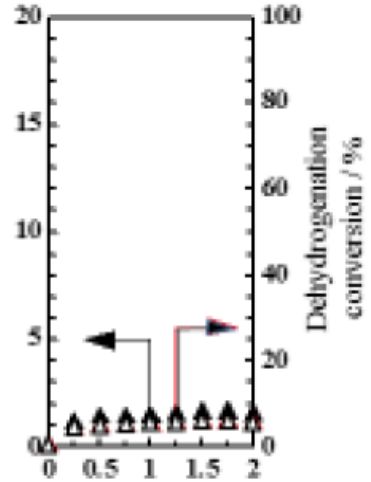

Reaction time / h

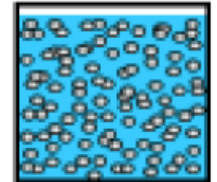

(c) Solid-liquid contact in suspetsded state

Figure 11: Dehydrogenation catalysis for methylcyclohexane in the batch-wise reactor. Relationship between reaction rates and charged amounts of substrate, with schematic description on immersed states of catalyst shown below.

Time courses of hydrogen generation with carbon-supported platinum-iridium catalyst at variously-charged amounts of methylcyclohexane. Charged amount: $0.4,0.8$, and $1.2 \mathrm{~mL}$. Catalyst: Composite nanoparticles supported on granular activated carbon (Pt-Ir (4:1)/C, 5 wt-metal\%, $0.30 \mathrm{~g})$. Reaction conditions: Boiling and refluxing by heating at $210^{\circ} \mathrm{C}$ and cooling at $5^{\circ} \mathrm{C}$.

In contrast, the reaction rates were not monotonous (Figure 14b). For all of the catalyst-layer temperatures $\left(225,285\right.$ and $\left.330^{\circ} \mathrm{C}\right)$, the maximum rate was obtained at the substrate feed of about $40 \mathrm{mmolmin}^{-1}$ among these continuous operations $\left(0.39 \sim 63 \mathrm{mmolmin}^{-1}\right)$. Low feed rates would decrease total molecules of contact with the catalytic sites. Excessively high rates would increase the possibility of channeling, with substrate contact to the catalytic sites disturbed. Dehydrogenation rates would therefore exhibit maximum with respect to the substrate feed rates.
Correlation plots between methylcyclohexane conversions and catalyst-layer temperatures together with the curve of equilibrium conversion at atmospheric pressure were summarized for platinum nano-particles supported on carbon cloth with different shapes and sizes, and with liquid substrate fed at various rates (Figure 15).

Continuous generation of hydrogen with use of a tubular flow reactor (Figure 2) was examined for various inlet rates of methylcyclohexane under 


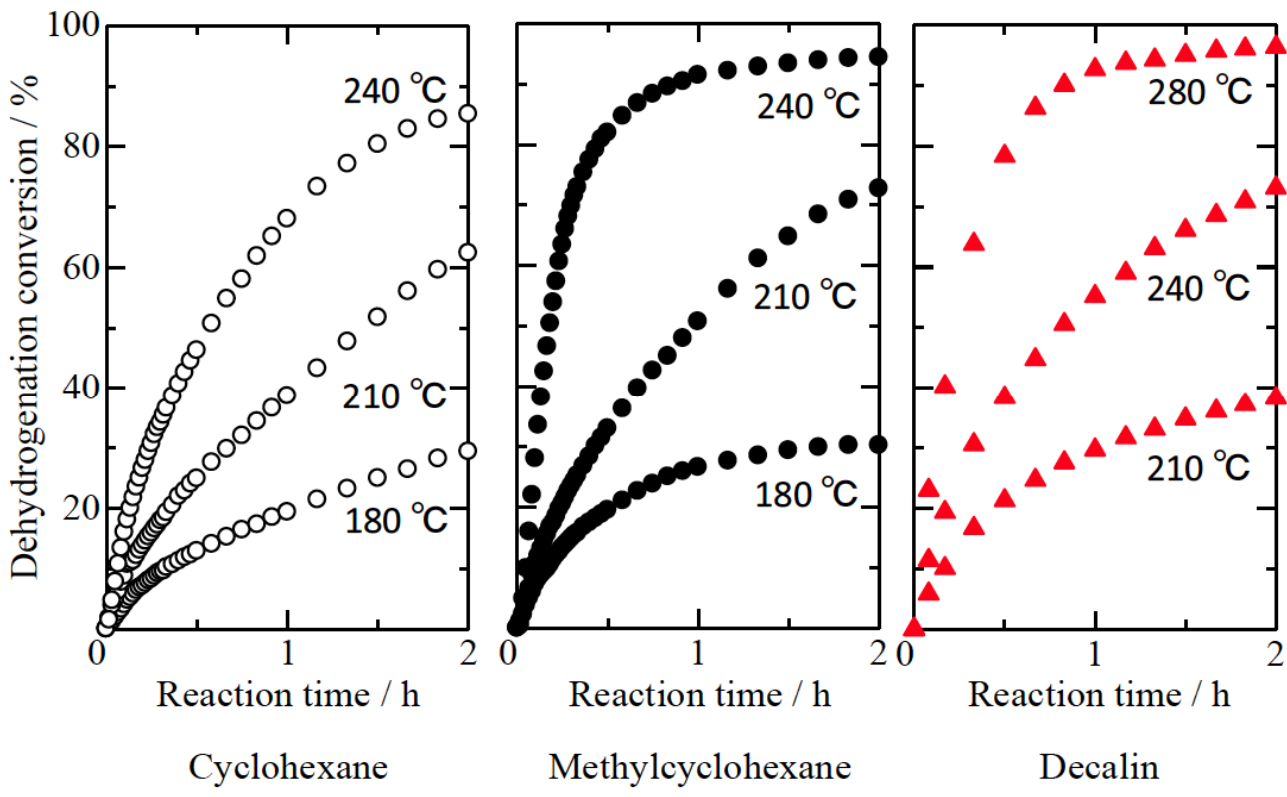

Figure 12: Comparison on dehydrogenation catalysis among naphthene substrates under superheated liquid-film conditions in the batch-wise reactor.

Time courses of hydrogen generation with carbon-supported platinum catalyst (Pt/C t wt $\%, 0.30 \mathrm{~g})$ immersed in substrate ( 1.0 $\mathrm{mL})$ by heating $\left(180,210,240\right.$, and $\left.280^{\circ} \mathrm{C}\right)$ and cooling $\left(5^{\circ} \mathrm{C}\right)$ under boiling and refluxing conditions.

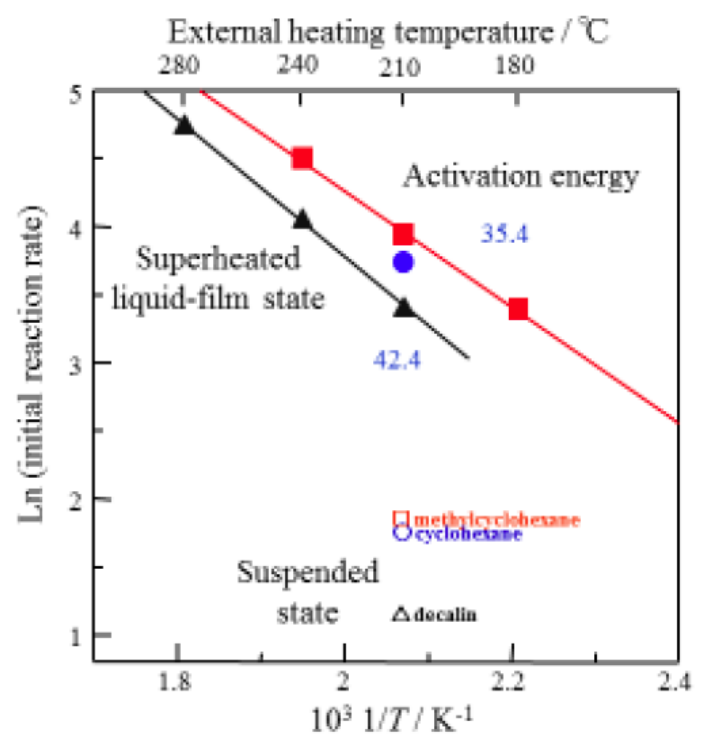

Figure 13: Comparison in plots between suspended state and superheated liquid-film state for catalytic naphthene dehydrogenation at $210^{\circ} \mathrm{C}$ and in lines of Arrhenius analyses for methylcyclohexane and decalin.

Initial reaction rates as a function of external heating temperature (Ln (rate) vs 1/T) with carbon-supported platinum catalyst (Pt/C $5 \mathrm{wt} \%, 0.30 \mathrm{~g})$ immersed in substrate (1.0 mL compared to $5.0 \mathrm{~mL}$ ) under boiling and refluxing conditions in the batch-wise reactor.

controlled catalyst-layer temperatures (Figure 16). The platinum nano-particles supported on granular activated carbon were laid at the upper part in the reactor tube. Liquid substrate was introduced from the downside part and heated. Temperatures were monitored with thermocouples at the positions of reactor inlet and outlet, preheating zone (two sites) and reacting zone (two sites). It was evident that the preheating zone itself was superheated, since the indicated temperatures $\left(\mathrm{ca} .170 \sim 220^{\circ} \mathrm{C}\right)$ were inbetween the boiling point $\left(101^{\circ} \mathrm{C}\right)$ and the catalyst-layer temperatures $\left(240 \sim 360^{\circ} \mathrm{C}\right)$.

Low feed rates would bring favorable conversions as the result of long periods of contact with catalyst. Contrastingly, hydrogen generation rates were unfavorable at low feed rates, as shown in Figure 17. Chances for the catalyst surface sites to meet with the substrate molecules would be increased with the feed rates. Anyhow, higher catalyst-layer temperatures brought larger reaction rates.

The outlet gaseous mixture of the tubular flow reactor can be separated by fractional distillation into hydrogen and the condensate, consisting of toluene and methylcyclohexane. Dehydrogenation was expected to proceed further by re-charging condensate mixtures to the reactor, where the same reaction conditions were imposed to methylcyclohexane with toluene addend at various compositions and temperatures (Figure 18). An inert carbon layer $(0.16 \mathrm{~g}$, $4 \mathrm{~cm}$ length) was used for preheating. Platinum nanoparticles supported on granular activated carbon ( $\mathrm{Pt} / \mathrm{C}$ $5 \mathrm{wt} \%, 0.04 \mathrm{~g}, 1 \mathrm{~cm}$ length) could therefore contact with 


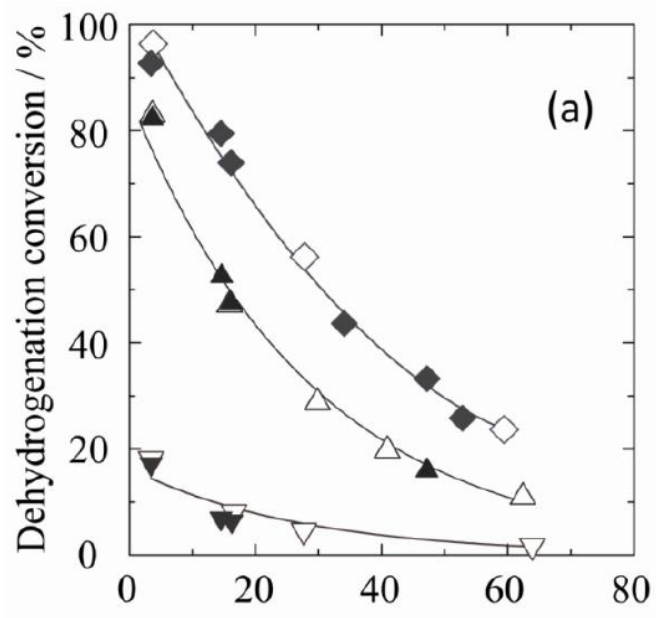

Rate of substrate feed / $\mathrm{mmol} \mathrm{min}^{-1}$

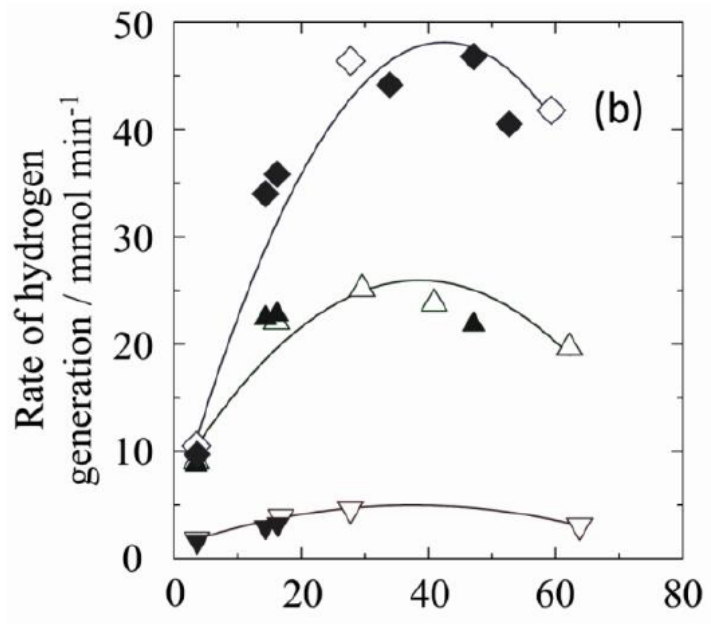

Rate of substrate feed $/ \mathrm{mmol} \mathrm{min}^{-1}$

Figure 14: Dehydrogenation catalysis for methylcyclohexane in a flow-type reactor. Correlation of feed rates with conversions (a) and rates of hydrogen generation (b).

Stationary magnitudes of conversion and hydrogen generation rate pursued with platinum nanoparticles supported on carbon cloth (Pt/C $5 \mathrm{wt} \%, 3 \mathrm{~cm} \Phi)$ at various temperatures monitored at the bottom of catalyst layer as $225^{\circ} \mathrm{C}(\nabla), 285^{\circ} \mathrm{C}(\Delta)$, and $330^{\circ} \mathrm{C}(\diamond)$, and various feed rates in both concentrated (open symbol) and dispersed (closed symbol) manners with respect to the density of holes for feeding substrate liquid.

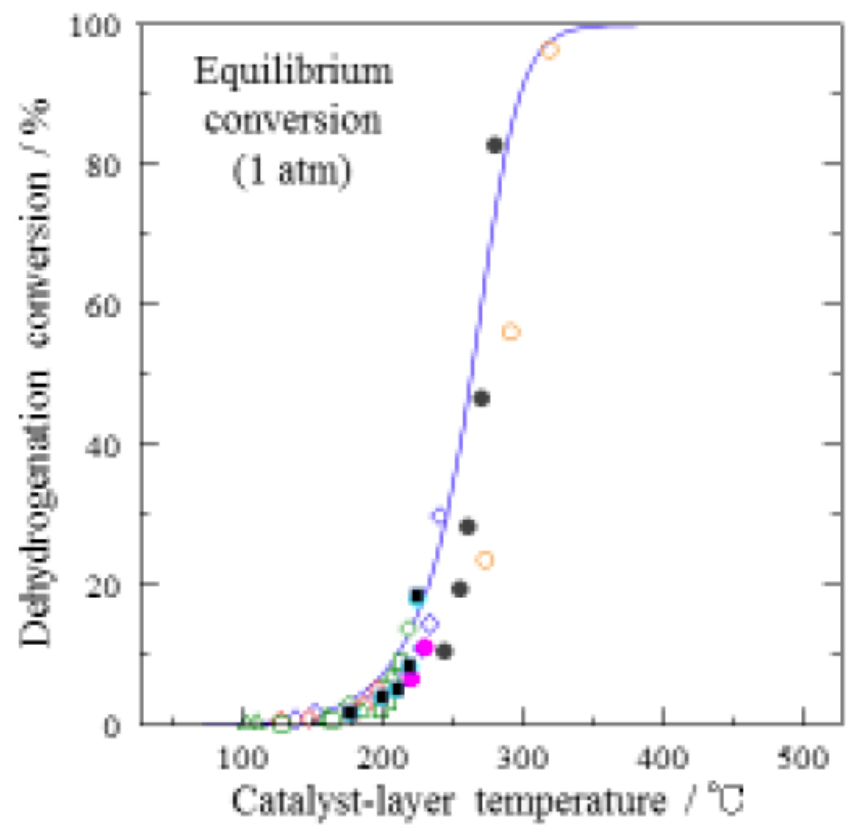

Figure 15: Dehydrogenation catalysis for methylcyclohexane in the flow-type reactor. Relationship between dehydrogenation conversions and catalyst-layer temperatures as varied with the amounts of platinum catalyst and the feed rates of substrate liquid.

Catalyst: Platinum nanoparticles supported on carbon cloth (Pt/C $5 \mathrm{wt} \%, 3 \sim 5 \mathrm{~cm} \Phi$ circular and $10 \times 20 \mathrm{~cm}^{2}$ rectangular). Feed rate : $0.3 \sim 2.1 \mathrm{~mL} \mathrm{~min}^{-1}$ for circular and $0.3 \sim 3.5 \mathrm{~mL} \mathrm{~min}^{-1}$ for rectangular.

superheated liquid. Under the conditions of inlet toluene concentrations $(8.5 \% \sim 32.7 \%)$ and the catalystlayer temperatures $\left(200^{\circ} \mathrm{C} 260^{\circ} \mathrm{C}\right)$, catalytic dehydrogenation was found to proceed further. Attained conversions were irrelevant to equilibrium conversions given for neat methylcyclohexane (curved line in the figure). By this reason, adoption of a twostaged tubular flow reactor was decided.

Double-staged tubular flow reactors could actually increase dehydrogenation conversions, in which the outlet condensates of the 1st-stage reactor were used 


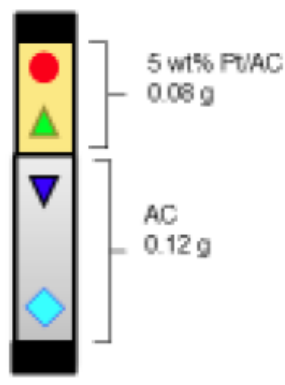

(a)

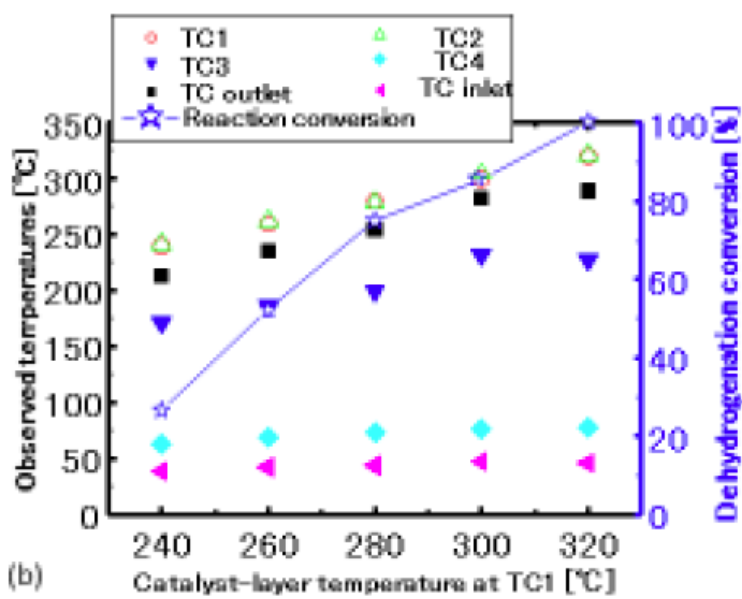

(b)

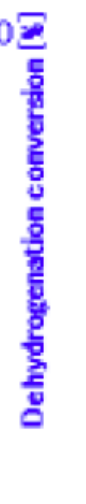

Figure 16: Dehydrogenation catalysis for methylcyclohexane in a tubular flow reactor, consisting of preheating zone (AC) and reaction zone $(\mathrm{Pt} / \mathrm{C})(\mathrm{a})$. Correlation of catalyst-layer temperatures with temperature distributions inside/outside the reactor and dehydrogenation conversions (b).

Catalyst: Platinum nanoparticles supported on granular activated carbon (Pt/C $5 \mathrm{wt} \%, 0.08 \mathrm{~g}$ filled at the upper part (2 cm) in the flow reactor (1/4 inch stainless tube)). Substrate feed: Liquid methylcyclohexane at ambient temperature introduced to the downside activated-carbon part $(0.12 \mathrm{~g}, 3 \mathrm{~cm})$ at the rate of $23.4 \mathrm{mmolh}^{-1}$.

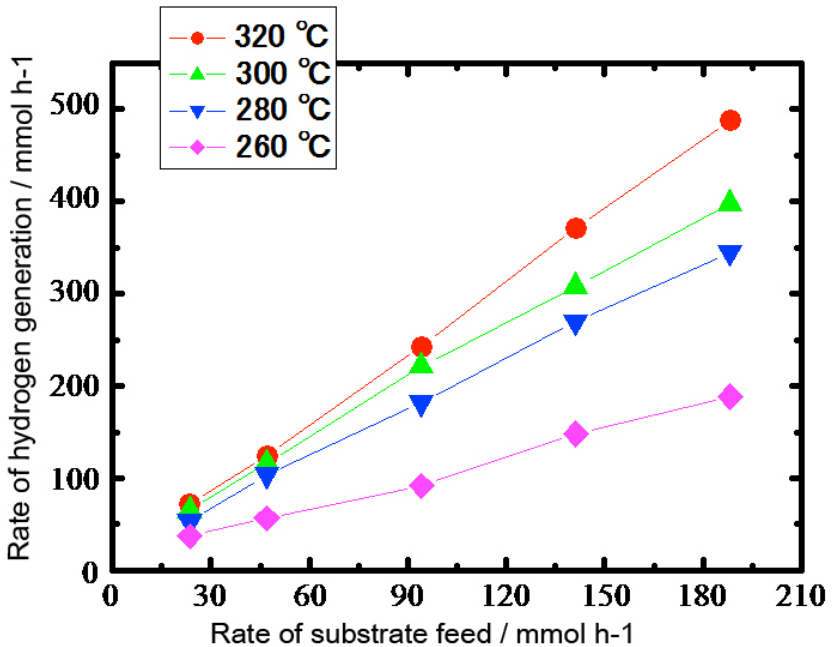

Figure 17: Dehydrogenation catalysis for methylcyclohexane in a tubular flow reactor. Relationship between the rates of hydrogen generation and the rates of substrate feed at various catalyst-layer temperatures.

Catalyst: Platinum nanoparticles supported on granular activated carbon (Pt/C $5 \mathrm{wt} \%, 0.08 \mathrm{~g}$ ). Substrate feed: Methylcyclohexane liquid introduced to the tube at the rate of $0.39,0.78,1.57,2.35$, and $3.14 \mathrm{mmol} \mathrm{min}^{-1}$.

as the inlet reactants of the 2 nd-stage one. At each catalyst-layer temperature from $200^{\circ} \mathrm{C}$ to $300^{\circ} \mathrm{C}$, further extents of reaction were confirmed, as shown in Figure 19. Finally-attained conversions i.e. the outlet compositions of the 2nd-stage reactor, were all exceeding the equilibrium-curve line of the neat substrate. It should be emphasized that perfect conversion was attainable at $300^{\circ} \mathrm{C}$. Ordinarily catalysis for this endothermic reaction requires higher temperatures than $350^{\circ} \mathrm{C}$ due to equilibrium restriction.

\section{DISCUSSION}

\subsection{Thermodynamical Backgrounds of Properly- Wetted Catalysis}

The inequality equation on chemical reactions of DeDonder (eq. 1) was developed by Prigogine to the extended inequality equation (eq. 2) [6].

$\mathrm{AV}>0$

$A_{1} V_{1}+A_{2} V_{2}>0$

Where $A$ is the chemical affinity and $V$ is the time derivative of reaction extent.

Among thermodynamical couples for chemical reactions, heat transfer would be included as a partner, which brings about large entropy production rates (eq. $3)$.

$A_{1} V_{1}=T\left(d_{i} S / d t\right)$

If this entropy term is sufficiently large $\left(T\left(d_{i} S / d t\right)\right.$ $>0$ ), the $A V$ term for the coupled reaction would become negative $\left(A_{2} V_{2}<0\right)$. Consequently, the chemical reaction can proceed $\left(V_{2}>0\right)$, even though no Gibbs energy is affirmative $\left(A_{2}<0\right)$.

The tensor order of heat flow and mass flow is classified as vector in common. Since Prigogine coupling [6] can be constituted between the same tensor order, it might be realized with nucleate boiling (Figure 20). Steep temperature gradients for nucleate 

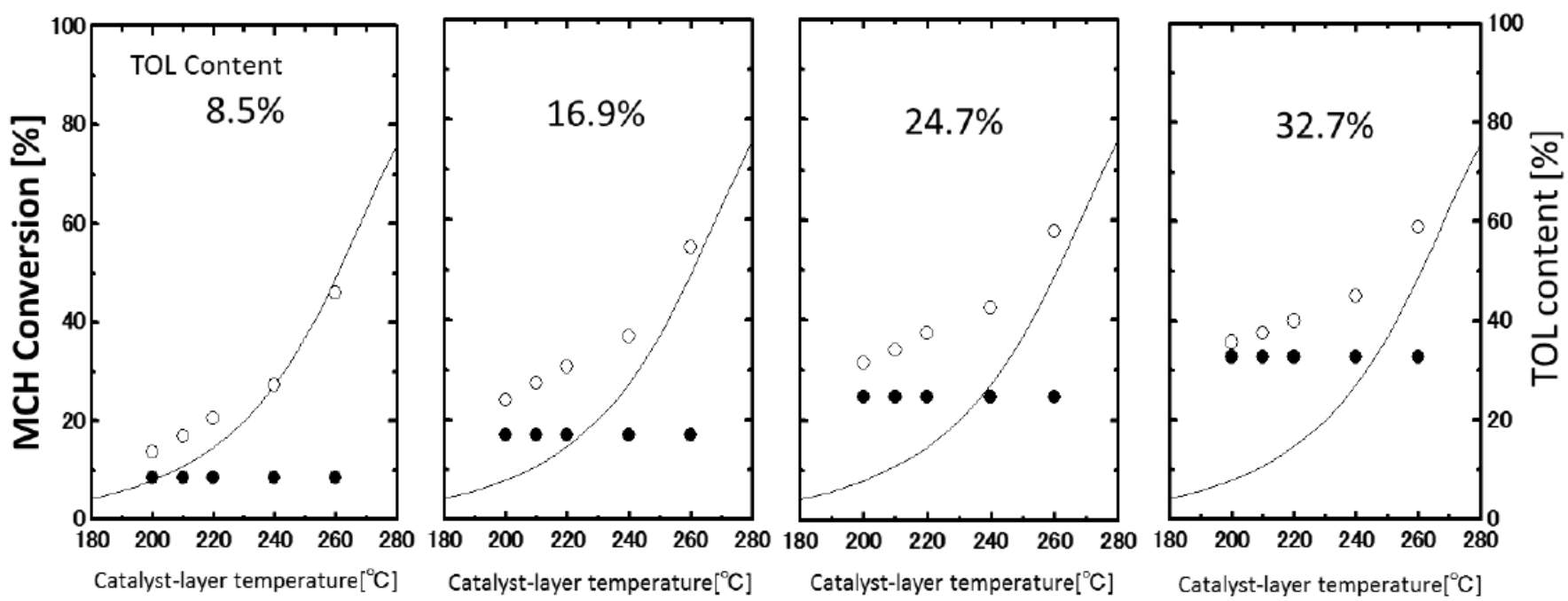

Figure 18: Dehydrogenation catalysis in a tubular flow reactor for methylcyclohexane, containing toluene addend initially at various concentrations. Rates of hydrogen generation correlated with substrate feed rates under various catalyst-layer temperatures.

Catalyst: Platinum nanoparticles supported on granular activated carbon ( $\mathrm{Pt} / \mathrm{C} 5 \mathrm{wt} \%, 0.08 \mathrm{~g}$ ). Substrate feed: Methylcyclohexane liquid introduced to the tube at the rate of $0.39,0.78,1.57,2.35$, and $3.14 \mathrm{mmol} \mathrm{min}^{-1}$.

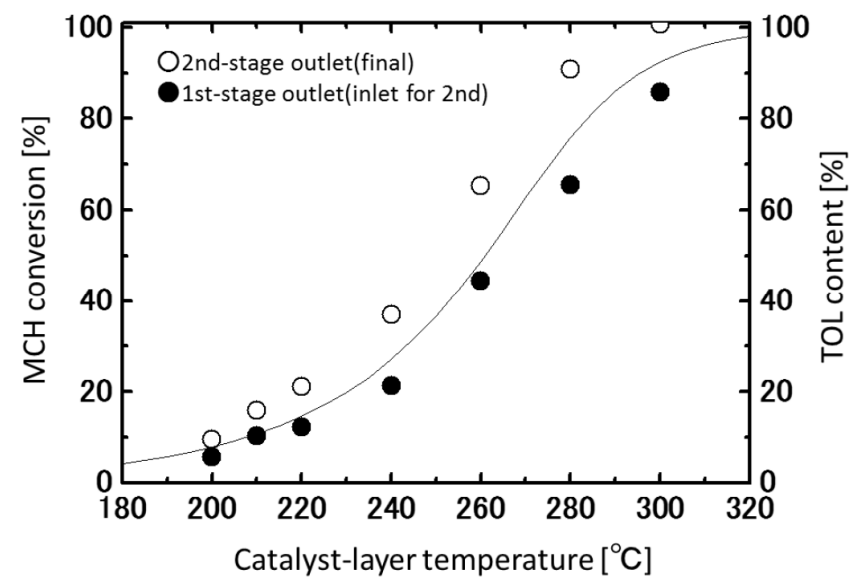

Figure 19: Dehydrogenation catalysis for methylcyclohexane in a two-staged tubular flow reactor. Two-stage performance from the MCH-TOL mixture, condensed as the first-stage output.

Catalyst: Platinum nanoparticles supported on granular activated carbon (Pt/C $5 \mathrm{wt} \%, 0.04 \mathrm{~g}$ laid at uppermost (1 $\mathrm{cm})$, with downside $(4 \mathrm{~cm})$ carbon support preceded for preheating). Substrate feed: 1st-stage input (MCH $0.39 \mathrm{mmol}$ $\mathrm{min}^{-1}$ ) converted into the substrate feed for 2 nd-stage input after condensation.

boiling will assure us high heat conductivities, though heat quantities are large. Irreversible mass flow will proceed at the bubble-evolving sites especially under enforced-fluid conditions [2]. Such processes that reaction products are expelled from the catalyst surface to the bubble space, and further to the gas space, will be repeated as the entropy-producing sequences (Figure 21). Rapid heat transfer will thus enhance efficient mass transfer, and vice versa.

\subsection{Necessary Conditions for Properly-Wetted Catalysis}

Properly-wetted nano-metal catalysts, supported on highly-porous activated carbon, had been chosen for efficient dehydrogenation [7-10]. Reasons of choice would be summarized as follows.

\section{Proper Liquid-to-Solid Ratio in Amounts}

As shown in Figures 3, 6 and $\mathbf{1 1}$ for 2-propanol, decalin and methylcyclohexane, respectively, a certain amount of solid catalyst must be immersed with a proper amount of substrate liquid initially in bach-wise operations. Scarce substrate amounts were easy to dry up partially or totally, resulting in suppressed dehydrogenation rates. On the contrary, substrate liquid in excess caused suspended states with no temperature gradient at the catalyst surface. Moreover, predominance of substrate evaporation from the bulk liquid (Figure 4) would not favor hydrogen generation by reflecting their endothermicity difference.

\section{Temperature Order of External Heating > Catalyst Layer > Boiling Point}

The catalyst-layer temperature was higher than the boiling point at the properly-wetted state, where hydrogen generation was most favored. Catalyst-layer temperatures at the properly-wetted state were raised in accordance with external heating temperature (Figure 9b), which brought enhanced catalytic activities (Figure 10). It is to be noted that the catalyst-layer temperature at the properly-wetted state was 


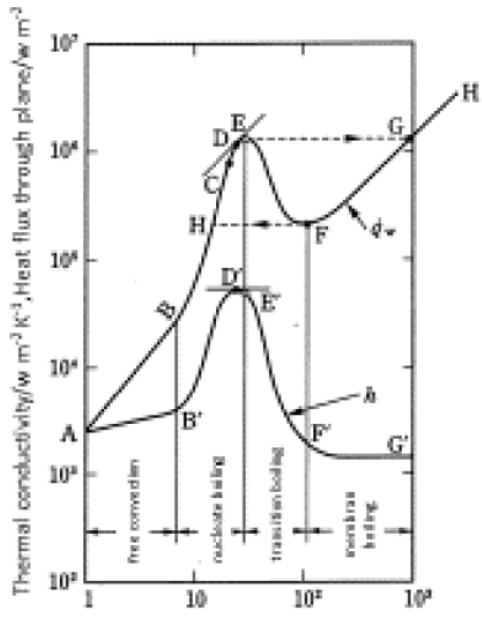

Degree of superheat Tw-To $[K]$

(a)Classification of boiling modes differentiated from superheated degree
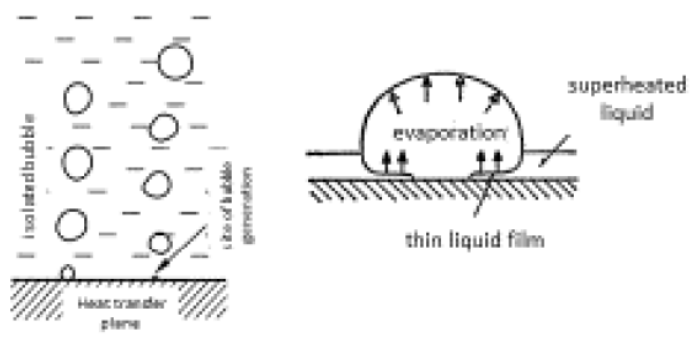

thin liquid film
(b)Definition of nucleate boiling and mechanism of highly-efficient heat transfer

Figure 20: Classification of boiling modes in focus on nucleate boiling as the most efficient mode for heat transfer.

\section{Chemical bond \\ cleavage on the catalyst surface}

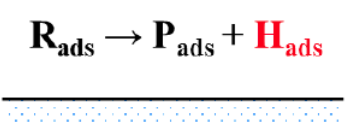

Adsorption \& reaction

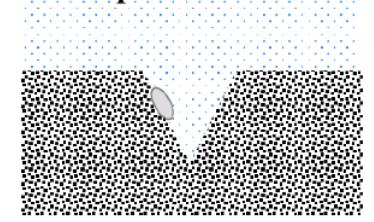

Removal to bubble from the catalyst surface

$$
\mathbf{P}_{\text {ads }} \rightarrow \mathbf{P}_{\text {gas }}, \mathbf{H}_{\text {ads }} \rightarrow \mathbf{H}_{\text {gas }}
$$

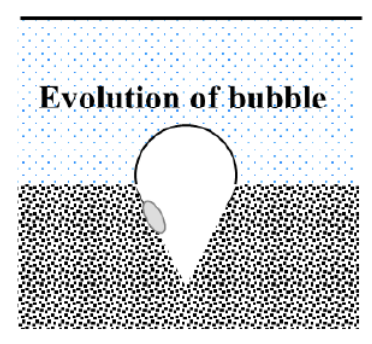

\section{Rapid replenishment toward the catalyst surface$$
\mathbf{R}_{\text {solu }} \rightarrow \mathbf{R}_{\text {ads }}
$$

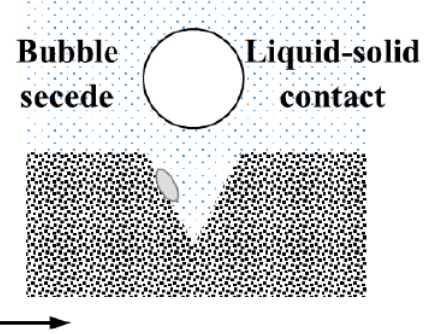

Arrow of time

Figure 21: Repeated irreversible processes for dehydrogenation of organic hydride under superheated liquid-film conditions.

Catalyst: Platinum nanoparticles supported on granular activated carbon (Pt/C 5 wt $\%$, 0.08 g). Substrate feed:

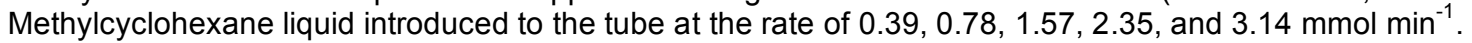

determined by the activated-carbon support irrespective of metallic species ( $\mathrm{Pt}$ only or $\mathrm{Pt}-\mathrm{Fe}$ composite, Figure $\mathbf{4 a}$, suggesting the importance of carbon micropores.

In the batch-wise experiments, external heating temperatures with use of oil-bath heat reservoir were $90^{\circ} \mathrm{C}$ for 2-propanol (bp: $82.4^{\circ} \mathrm{C}$ ), $210-280^{\circ} \mathrm{C}$ for decalin (bp: $192^{\circ} \mathrm{C}$ ) and $180-240^{\circ} \mathrm{C}$ for methycyclohexane (bp: $\left.101^{\circ} \mathrm{C}\right)$. True reaction temperatures at the bubbleevolving sites of nucleate boiling or the temperatures of superheated substrate liquid are not yet known. However, essential importance of properly-wetted catalysis lies not on the reaction temperature itself but on the temperature gradient from the supporting carbon, which is detectable, to the immeasurable catalytically-active sites. Activation energies were obtained from the rate dependence on heating temperatures (Figures 10 and 13), which would partly reflect the surface densities of vacant active sites generated by enforced bubble removal from catalyst.

\section{How to Accomplish Perfect Conversion}

On account of thermodynamical characteristics of dehydrogenation: $\Delta H>0$ and $\Delta S>0$, equilibrium conversions will decrease at low reaction temperatures. The turning temperature for 2-propanol is $164.7^{\circ} \mathrm{C}$, at which $50 \%$ conversion $\left(\Delta G^{\circ}=0\right)$ is attained. As for 
dehydrogenation of 2-propanol, equilibrium limit of 12.6 $\%$ conversion at $90^{\circ} \mathrm{C}$ was overcome by reactive separation (Figure 5, the case of solid-gas contact), whereas $83 \%$ conversion was found to be realized by adopting the properly-wetted state (Figure $\mathbf{5}$, the case of solid-liquid contact).

The flow-type experiments have demonstrated for dehydrogenation conversions to increase with diminished supply rates of substrate liquid (Figure 14), which would be ascribed to prolonged contact for the catalyst with substrate molecules. Conversions were favored at elevated catalyst-layer temperatures, as elucidated for $\mathrm{Pt}(5 \mathrm{wt} \%)$ nano-particles on both carbon cloth (Figure 15) and carbon granules (Figure 16) in harmony with equilibrium predictions.

In the tubular flow reactor, liquid mixtures of substrate methylcyclohexane and product toluene were found to evolve hydrogen at various levels of toluene contents and catalyst-layer temperatures (Figure 18). A double staged rector was therefore designed: the firststage output was fractionated to separate hydrogen from a methylcyclohexane-toluene mixture, which was fed to the second stage in liquid in order to proceed the reaction further (Figure 19). Perfect conversion was demonstrated at $300^{\circ} \mathrm{C}$ beyond the equilibrium conversion by adopting this two-staged flow reactor upon the concept of the properly-wetted state.

\subsection{Compact Feed of Hydrogen from MCH to SOFC (Enefarm)}

Continuous generation of hydrogen $\left(490 \mathrm{mmolh}^{-1}\right)$ from the liquid feed of methylcyclohexane $\left(192 \mathrm{mmolh}^{-}\right.$ $\left.{ }^{1}\right)$ was observed with use of the granular $\mathrm{Pt} / \mathrm{C}(5 \mathrm{wt} \%)$ catalyst at $320^{\circ} \mathrm{C}$ (Figure 17). The extent of conversion
$85.1 \%$ was derived as the ratio from the above two rates of hydrogen generation and methylcyclohexane feed, whereas perfect conversion had been observed at the reduced feed rate $\left(23.4 \mathrm{mmolh}^{-1}\right)$. These experiments were performed with the same catalyst and temperature (Figure 16). Long contact period due to diminished substrate flow is favorable to conversions. In contrast, large amounts due to high feed rates would enhance catalytic reaction rates.

The tubular flow reactor has an inside volume of $0.743 \mathrm{~mL}$, consisting of a preheating zone $(3 \mathrm{~cm})$ and a catalyst zone $(2 \mathrm{~cm})$. Total catalyst volume of the twostaged reactor ought to be $0.594(=0.743 \times 2 / 5 \times 2)$ $\mathrm{mL}$. Liquid hourly space velocity of $41.0 \mathrm{~h}^{-1}$ will be attained at perfect conversion toward the adopted feed

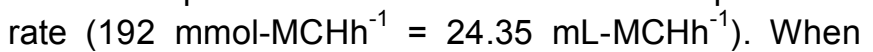
the conversion of $85.1 \%$ had been attained in the $1 \mathrm{st}$ reactor at $320^{\circ} \mathrm{C}$, perfect conversion in the 2 nd reactor would be realized at the catalyst-layer temperature of $320^{\circ} \mathrm{C}$. Heating temperatures of $350 \sim 400^{\circ} \mathrm{C}$ would sufficiently be enough to enable perfect conversion for large feed rates of methylcyclohexane.

The magnitude of LHSV for Spera Hydrogen ${ }^{\circledR}$ was reported as $2.0 \mathrm{~h}^{-1}$ by Chiyoda Chemical Corporation [11], which seems to be a typical magnitude as gas/solid catalysis. In other words, LHSV of $41.0 \mathrm{~h}^{-1}$ for properly-wetted catalysis is so huge that a dehydrogenation reactor can be designed in a compact manner. Contrast between these two types of catalysis is summarized in Table 1. Data for properly-wetted catalysis with adoption of a two-staged reactor was cited from Figure 19.

Solid oxide fuel cell (SOFC), driven with hydrogen from methylcyclohexane, attracts our special attention

Table 1: Contrast in Characteristics of Properly-Wetted Catalysis with Gas/Solid Catalysis for Dehydrogenation of Methylcyclohexane

\begin{tabular}{|c|c|c|}
\hline & Properly-Wetted Catalysis & Gas/Solid Catalysis \\
\hline \hline Microeversibility during reaction & No & Yes \\
\hline Substrate in contact with catalyst & Liquid phase & 0.0446 \\
\hline Substrate density [mol-MCH/L] & 7.88 & $4.72 \times 10^{6}$ \\
\hline Catalyst volume $[\mathrm{mL}]$ & 1.485 & $94.4 \times 10^{3}$ \\
\hline Substrate feed rate in liquid $[\mathrm{mL}-\mathrm{MCH} / \mathrm{h}]$ & 2.97 & $50.0 \times 10^{3}$ \\
\hline Product generation rate $[\mathrm{NL}-\mathrm{H} 2 / \mathrm{h}]$ & 1.57 & 350 \\
\hline Catayst-layer temperature $\left[{ }^{\circ} \mathrm{C}\right]$ & 300 & $>99$ \\
\hline Extent of conversion attained $[\%]$ & $>99$ & Ref. [11] \\
\hline Data source & Figure 19 & \\
\hline
\end{tabular}




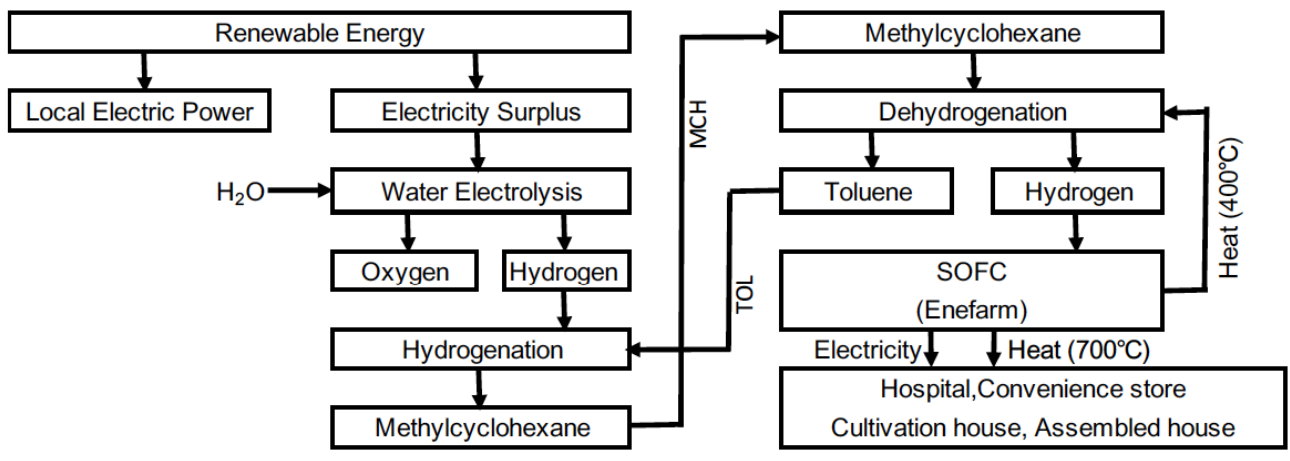

RE Supply Site

\section{Energy Demand Site}

Figure 22: Energy supply chain started from renewable energy and aimed to electricity and heat of SOFC (Enefarm) by mediation of organic hydride.

to Enefarm scales (700 $\mathrm{w}$ and $5 \mathrm{kw}$ ) [12] on the following grounds.

1) Since enthalpy change of methylcyclohexane dehydrogenation $\left(67.5 \mathrm{~kJ} / \mathrm{mol}^{-\mathrm{H}_{2}}\right)$ is much smaller than the combustion heat of hydrogen $\left(241.8 \mathrm{~kJ} / \mathrm{mol}-\mathrm{H}_{2}\right)$, the endothermicity is reconciled with the exhaust heat from SOFC.

2) The exothermic temperature of SOFC $\left(700^{\circ} \mathrm{C}\right)$ is sufficiently higher than the endothermic temperature for hydrogen generation afforded from methylcyclohexane $\left(350 \sim 400^{\circ} \mathrm{C}\right)$.

3) In order to operate Enefarm SOFC (700 w), it is necessary to supply hydrogen of $23.94 \mathrm{~mol}^{-\mathrm{H}_{2} \mathrm{~h}^{-1}}$ or to feed substrate of $7.98 \mathrm{~mol}-\mathrm{MCHh}^{-1}$ at perfect conversion. The observed hydrogen generation rate at $320^{\circ} \mathrm{C}$ as well as the activation energy of $100.9 \mathrm{~kJ} \mathrm{~mol}^{-1}$ would allow designing a new flow reactor under $350 \sim 400^{\circ} \mathrm{C}$ conditions. Metallic species, including any composite one, must be selected on the basis of both catalytic activities and preparation costs.

4) Storable and transportable merits of the $\mathrm{MCH} / \mathrm{TOL}$ hydrogen carrier are useful to any demand in small scales and/or emergency use at convenience stores or hospitals e.g. LED illumination or steam disinfection for medical operations in a hospital.

5) Dispersed sources of renewable energies will generate hydrogen via water electrolysis and produce methylcyclohexane as a safe, easy-tohandle and cost-effective hydrogen carrier. Reproduction from toluene will be performed with an adequately-sized equipment and tiny exergy- loss operation, if compared to liquefaction of hydrogen. Moreover, both methylcyclohexane and toluene are commodity chemicals suitable for over-land and over-sea transport.

Energy supply chain from renewable energy to SOFC would thus be supported with the $\mathrm{MCH} / \mathrm{TOL}$ hydrogen carrier. A storage tank $(90$ L) of methylcyclohexane will give hydrogen to SOFC $(700 \mathrm{w})$ for four days continuously. Compact design of a twostaged catalytic reactor coupled with Enefarm SOFC would make it possible to provide combined heat and power to hospitals, combinience stores, cultivation houses, assembled houses and so on (Figure 22) [13].

\section{CONCLUSION}

Upon the basis of superheated liquid-film concept, organic hydrides were attempted to generate hydrogen under nucleate boiling conditions with use of nanometal particles supported on highly-porous carbon.

Steep temperature gradient toward properly-wetted catalysts was found to afford perfect conversion as well as high LHSV. Methylcyclohexane hydrogen was affirmatively verified for SOFC (Enefarm) operation. Heating temperatures at $350 \sim 400^{\circ} \mathrm{Cw}$ will be adequate for thermal cascade utilization of SOFC exhaust heat $\left(700^{\circ} \mathrm{C}\right)$.

Newly-designed compact reactors for supplying hydrogen to SOFC ( $700 \mathrm{w}$ and $5 \mathrm{kw}$ ) would take an anticipated mediator role between renewable energy supply and local energy demand.

\section{REFERENCES}

[1] Gupta RB. Hydrogen Fuel-Storage, Transport and Utilization, CRC Press, New York 2008; Chapt. 1 \& 13. 
[2] Aihara T. Heat Transfer Engineering, Shokabo Press. Tokyo, 1994; Chapt. 5.3.5. "Enforced Fluid Boiling".

[3] Shono A, Saito Y. Technology Assembly for Utilization of Hydrogen. NTS Press, 2014; Chapt. 2.6.1. "Organic Hydride for Storage \& Transport System of Hydrogen".

[4] Saito Y. Engineering System for Fine Particles - Applied Technology II (Ed. H. Yanagida), Fuji Techno-system Press, Tokyo 2002; Chapt. 9.2.2. "Metal Fine Particle Catalyst".

[5] Hodoshima S, Takaiwa S, Shono A, Satoh K, Saito Y. Appl Catal A: General 2005; 283: 235-242. https://doi.org/10.1016/j.apcata.2005.01.010

[6] Glansdorff G, Prigogine I. Thermodynamic Theory of Structure, Stability and Fluctuations, Wiley, London 1971; Chapt. 3.

[7] Hodoshima S, Shono A, Saito K, Saito Y. Stud Surf Sci Catal 2006; 159: 177-180. https://doi.org/10.1016/S0167-2991(06)81562-4

[8] Shono A, Hashimoto T, Hodoshima S, Satoh K, Saito Y. J Chem Eng Jpn 2006; 39: 211-215. https://doi.org/10.1252/jcej.39.211
[9]

Hodoshima S, Shono A, Saito Y. Energy Fuels 2008; 22: 2559-2569. https://doi.org/10.1021/ef700607h

[10] Saito Y, Aramaki K, Hodoshima S, Saito M, Shono A, Kuwano J, Otake K. Chem Eng Sci 2008; 63: 4935-4941. https://doi.org/10.1016/j.ces.2007.11.036

[11] Okada Y. Energy Catalyst Technology, Muroi T, Ed. Science \& Technology Press, Tokyo, "Catalyst Technology for Hydrogen Storage and Transport System with Use of Organic Hydride" 2010; Chapt. 7.2.

[12] NEDO, White Paper on Hydrogen Energy. Nikkan Kogyo Newspaper Press, "Domestic, Business \& Industrial Use of Fuel Cell" 2015; Chapt. 6.5.1-2.

[13] Saito Y, Okada Y. Energy Technology Roadmap of Japan: Future Energy Systems Based on Feasible Technologies Beyond 2030, Kato Y, Koyama M, Nakagaki T, Eds., Springer, London, Topics in Primary and Secondary Sectors of Industry, "Organic Hydride for Hydrogen Energy Carrier" 2016; Chapt. 6

Received on 15-07-2016

Accepted on 10-10-2016

Published on 02-01-2017

DOI: http://dx.doi.org/10.6000/1929-6002.2016.05.04.1

(C) 2016 Shono et al.; Licensee Lifescience Global.

This is an open access article licensed under the terms of the Creative Commons Attribution Non-Commercial License (http://creativecommons.org/licenses/by-nc/3.0/) which permits unrestricted, non-commercial use, distribution and reproduction in any medium, provided the work is properly cited. 